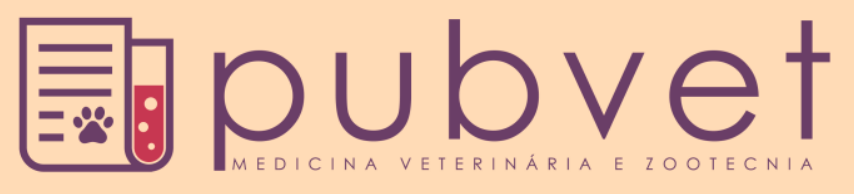

https://doi.org/10.22256/pubvet.v12n3a51.1-6

\title{
Aspectos relevantes na produção comercial de embriões bovinos por meio da técnica biotecnológica de fertilização in vitro: Revisão
}

\author{
Anselmo Alves Lustosa ${ }^{\ominus 1}$, Nayla Andrade Barboza ${ }^{\ominus 2}$, Yago Gabriel Da Silva Barbosa ${ }^{\bullet}$ 3*, $^{*}$ \\ Pamela Karoliny Oliveira Rodrigues ${ }^{4}$, Francisco da Chagas Ribeiro Magalhães Neto ${ }^{\bullet}$
}

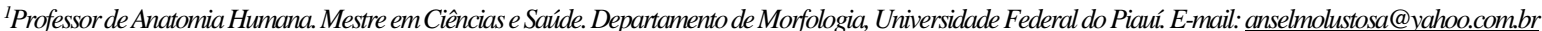

${ }^{2}$ Médica. Mestre em Ciências e Saúde. Departamento de Medicina Comunitária, Universidade Federal do Piauí, Brasil

${ }^{3}$ Médico Veterinário. Mestrando em Ciência Animal, Universidade Federal do Piauí, Brasil

${ }^{4}$ Nutrição. Graduanda em nutrição. Faculdade Mauricio de Nassau, Brasil

${ }^{5}$ Médico Veterinário. Mestrando em Ciência Animal, Universidade Federal do Piauí, Brasil

Autor para correspondência, E-mail:y.ago.gabriel@hotmail.com

\begin{abstract}
RESUMO. A economia nacional sofreu inúmeras modificações nas últimas décadas no setor pecuário; essas modificações relacionam-se ao desenvolvimento e aplicação comercial de biotecnologias da reprodução visando aumentar a velocidade com a qual o melhoramento genético vem sendo realizado. Destaque-se a técnica de Fertilização In vitro que é uma tecnologia disponível para todo o território nacional, e vem sendo utilizada amplamente. Sendo uma biotecnia recente a produção in vitro de embriões visa a obtenção de embriões fora do aparelho reprodutivo da fêmea, para isso são necessárias algumas etapas como a maturação in vitro de oócitos, fertilização in vitro, e o cultivo in vitro. A identificação e seleção de receptoras de alta qualidade não são simples e possui relevância para o sucesso da atividade. Vários estudos têm relatado as variáveis que influenciam nos resultados da sincronização de receptoras. A partir desse estudo acredita ser que o Brasil continuará liderando na produção de embriões In vitro e passará a fornecer cada vez mais genética a países interessados.
\end{abstract}

Palavras chave: produção, embriões, receptoras

\section{Relevant aspects in the commercial production of bovine embryos through the biotechnological technique of in vitro fertilization: Review}

\begin{abstract}
The national economy has undergone numerous changes in recent decades in the livestock sector, such changes are related to the development and commercial application o reproductive biotechnologies to increase the speed with which genetic improvement is being realized as a highlight and the technique of In vitro fertilization and available formation wide technology, and has been widely used. Being a recent biotech in vitro production of embryos aims to obtain embryos outside their productive tract of the female for it are a few steps as in vitro maturation of oocytes, in vitro fertilization, and cultivation in vitro. The identification and selection of recipients of high quality are not simple and has relevance to the success of the activity. Several studies have reported variables that influence the result of the synchronization of recipients. From this study believed to be that Brazil will continue to lead in the production of in vitro embryos and will provide the genetic increasingly interested countries.
\end{abstract}

Keywords: production, embryos, receptor 


\title{
Aspectos relevantes en la producción comercial de embriones bovinos por medio de fertilización in vitro: Revisión
}

\begin{abstract}
RESUMEN. La economía nacional sufrió numerosas modificaciones en las últimas décadas en el sector pecuario, tales modificaciones se relacionan con el desarrollo y aplicación comercial de biotecnologías de la reproducción objetivando aumentar la velocidad con la cual el mejoramiento genético viene siendo realizado. Se destaca la técnica de Fertilización In vitro que es una tecnología disponible para todo el territorio nacional, y viene siendo utilizada ampliamente. Siendo una biotecnología reciente la producción in vitro de embriones objetiva la obtención de embriones fuera del aparato reproductivo de la hembra, para ello son necesarias algunas etapas como la maduración in vitro de ovocitos, la fertilización in vitro, y el cultivo in vitro. La identificación y selección de receptoras de alta calidad no son simples y tienen una relevancia para el éxito de la actividad. Varios estudios han reportado variables que influencian el resultado de la sincronización de receptoras. A partir de ese estudio se cree que Brasil pueda seguir liderando la producción de embriones In vitro y pasará a proporcionar cada vez más genética a países interesados.
\end{abstract}

Palabras clave: Producción, embriones, receptoras

\section{Introdução}

A economia nacional sofreu inúmeras modificações nas últimas décadas no setor pecuário, tais modificações relacionam-se ao desenvolvimento e aplicação comercial de biotecnologias da reprodução visando aumentar a velocidade com a qual o melhoramento genético vem sendo realizado.

O desenvolvimento da biotecnologia no Brasil permitiu uma maior aplicação e a exportação de modelos adotados para vários países latinoamericanos e de outros continentes (Bols et al., 2012). Após o conhecimento de técnicas de obtenção de embriões in vivo, o país passou a dominar a PIV, ocupando uma posição importante no mercado de embriões bovinos, principalmente, por possuir o maior rebanho comercial do mundo e ser o principal exportador de carne bovina (Seneda et al., 2002).

A técnica de fertilização in vitro é uma tecnologia disponível para todo o território nacional, e vem sendo utilizada amplamente. Isso se fez possível por conta do surgimento uma interessante rede de atendimento, onde os laboratórios de biotecnologia passaram a atuar nos estados mais longínquos, dessa forma originou-se então um processo que permite uma logística mais flexível por parte das equipes de coleta e de transferência (ABCZ, 2014).

Em 2005, o Brasil firmou-se como o país de maior aplicação de biotecnologias da reprodução em bovinos no mundo (Viana \& Camargo, 2007)). Atualmente, o Brasil é considerado o maior produtor de embriões de fertilização in vitro no mundo, com produção que corresponde a $85 \%$ do mercado mundial, considerando todas as raças (ABCZ, 2014). Certamente há um predomínio da raça Nelore, tanto no processo de produção e comercialização quanto pela valorização dos embriões devido aos altos preços muitas vezes alcançados nesta raça (Pontes et al., 2011).

O sucesso desta tecnologia depende, em grande parte, da resposta à superovulação e essa pode ser influenciada por fatores relacionados com $\mathrm{o}$ tratamento super-ovulatório, ou em maior grau por fatores individuais associados às características da dinâmica folicular ovariana (Bó et al., 2000) ou até mesmo a condição ovariana no momento da super ovulação (Monniaux et al., 1983).

A produção in vitro (PIV) foi intensivamente aperfeiçoada, o que conotou nos últimos anos notável avanço no melhoramento genético. Nos últimos cinco anos a disseminação destas técnicas no País atingiu grande relevância. Diante do que foi descrito acima, este estudo teve como objetivo a realização de uma revisão de literatura focada na obtenção de maiores conhecimentos inerentes a produção in vitro dos embriões bovinos.

\section{Produção in vitro}

A expandiu-se após o nascimento de Louise Brown em 1978, na Inglaterra. Este foi considerado o primeiro bebê de proveta (Edwards, 1981). Dai então em 1982 nasceu o primeiro bovino obtido por fecundação in vitro nos Estados Unidos (Brackett et al., 1982). O fato de a fêmea Bos taurus indicus produzir dezenas de oócitos em 
um único procedimento de aspiração folicular comum a relação direta com o número de folículos (Pontes et al., 2009). Por meio desta biotécnica pode-se obter uma produção média de uma gestação por vaca/semana, o que permite uma rápida multiplicação de genótipos superiores previamente selecionados e uma diminuição no intervalo de gerações, propiciando uma maior intensidade de seleção, do que por outros processos como a transferência de embriões. (Yang et al., 2013). Fisiologicamente as fêmeas Bos taurus taurus e Bos taurus indicus apresentam algumas diferenças. Rigolon et al. (2009), Rigolon et al. (2003) verificaram similaridade entre a população de folículos pré-antrais de fetos e novilhas além de variação individual significativa na quantidade dos folículos das duas categorias estudadas (Rubin et al., 2009),

Independente da espécie estima-se que a PIV possa aumentar o ganho genético anual acima de $10 \%$, quando aplicada apropriadamente, principalmente pela possibilidade de cruzamentos fatoriais, diminuindo a taxa de consanguinidade, bem como pela utilização de fêmeas pré-púberes. Além disso, com a PIV pode-se ter uma produção maciça de animais mestiços, possibilitando a manutenção de rebanhos com o grau de sangue desejado, o que é impossível com o uso da monta natural e inseminação artificial (Sugimoto, 2012).

Sendo uma biotécnica recente a produção in vitro de embriões visa à obtenção de embriões fora do aparelho reprodutivo da fêmea. Envolve a coleta de oócitos dos folículos ovarianos, completando três etapas biológicas: Maturação in vitro de oócitos (MIV), fertilização in vitro (FIV) e o cultivo in vitro (CIV) (Hafez \& Hafez, 2004). Os procedimentos realizados geralmente são laparotomia ventral média, laparoscopia após superovulação (SOV) (Lambert et al., 1983).

\section{A técnica de aspiração folicular orientada por ultrassonografia (OPU)}

A OPU foi desenvolvida para atender à demanda por um procedimento para coleta de complexo cumulus-oócito o objetivo seria o uso de uma técnica menos traumática que as abordagens cirúrgicas até então utilizada. A grande vantagem da técnica está o fato de ser pouco invasiva, outra peculiaridade muito importante e o fato de não depender de préestimulação hormonal, podendo ser usada em qualquer fase do ciclo estral, em animais prépúberes e inclusive em animais que apresentam gestação inicial (Viana \& Bols, 2005). A OPU é uma técnica muito versátil e permite a utilização de animais muito jovens, a partir de dois a 3 meses, ou senior. Não interfere no estado fisiológico do animal, não requere estimulação hormonal exógena e pode ser executada duas vezes por semana (Galli \& Lazzari, 2000). Pode ainda ser usada para gerar produtos adicionais de uma vaca de alto valor que não responda mais aos tratamentos utilizados nas coletas de embriões, também naquelas que apresentam infertilidade adquirida devido a patologias no trato reprodutivo, impossibilitando a fecundação e o desenvolvimento embrionário in vivo (Bols et al., 2012). O primeiro requisito para o sucesso da produção in vitro de embriões é a obtenção de oócitos de boa qualidade, com boas características morfológicas e de desenvolvimento, tais características dependem do tamanho do folículo de origem e a extensão e integridade das células do cumulus influenciam a competência oocitária (Sirard, 2017).

Dependendo do método de recuperação, claramente pode se observa um impacto na morfologia do CCOs e subsequentemente na capacidade de desenvolvimento in vitro. A importância das células do cumulus estarem intactas para a maturação oocitária e para o desenvolvimento in vitro não deve ser subestimada (Sirard, 2017).

\section{Maturação e fertilização in vitro}

$\mathrm{O}$ processo de maturação in vitro inicia com a chegada dos oócitos aspirados ao laboratório, estes são mantidos em um meio de maturação. $\mathrm{O}$ período necessário para a maturação nuclear e espécies especifico, sendo que para a espécie bovina a maturação nuclear do oócito requer um período de 18 a 22 horas (Hafez \& Hafez, 2004).

$\mathrm{O}$ meio de cultura mais utilizado para a maturação de oócitos é o TCM 199 acrescido de $10 \%$ de soro bovino, FSH, LH, estradiol e EGF. E necessária à utilização de uma incubadora de $\mathrm{CO}_{2}$ (Galli \& Lazzari, 2000), sendo uma temperatura ideal $39^{\circ} \mathrm{C}$ em atmosfera a $5 \%$ de $\mathrm{CO}_{2}$ em ar e umidade saturada (Gonçalves et al., 2002).

Fim dado a etapa de maturação, os oócitos precisam ser fecundados para que sejam capazes de se desenvolver até o estágio de blastocisto. Desta forma, deve ser feito o processamento do sêmen realizando-se uma seleção espermática e capacitação espermática. Após a capacitação dos espermatozoides, retira-se da estufa a placa de 
petri contendo os ovócitos maturados e depositam-se os espermatozoides, sempre procurando proporcionar um ambiente adequado (Gonçalves et al., 2002).

O dia da fertilização é considerado como o dia zero (D0). A fusão do oócito com o espermatozoide ocorre após a penetração, especificamente pelo contato entre o segmento equatorial do espermatozoide e a membrana plasmática do oócito (Sirard, 2017).

\section{Cultivo in vitro}

O ponto mais importante no cultivo embrionário é o uso de meios que suporte a nutrição celular e o desenvolvimento durante a fase de pré-implantação embrionária. A composição do meio deve simular o ambiente e os fluidos do útero e do oviduto durante o início da gestação. O SOF é composto por secreções das células epiteliais, a partir da difusão de nutrientes do plasma. O potássio e o cloro estão presentes no fluido de oviduto em concentrações mais elevadas do que nas do plasma, enquanto o nível de cálcio é mais baixo e os de sódio e magnésio são similares ao do soro (Gonçalves et al., 2002).

Vários estudos têm demonstrado a utilização com sucesso de meios definidos de cultura, adicionando o PVA em substituição ao BSA e assim evitando a aderência dos embriões e as substâncias não conhecidas do BSA. No entanto, embriões cultivados em meios totalmente definidos, normalmente sofrem bloqueio no desenvolvimento e redução da viabilidade em relação àqueles cultivados em meios suplementados com BSA e SFB (Keskintepe \& Brackett, 1996).

Outros estudos demonstraram que a substituição de SFB e BSA por PVA proporciona baixo desenvolvimento embrionário, particularmente no estádio de blastocisto. Assim, sugerindo que o desenvolvimento de mórula para blastocisto exige fatores adicionais exógenos que podem ser encontrados no SFB, provavelmente estimula diferenciação e a proliferação celular (Lim et al., 1999).

Parece que a albumina exerce importante papel com relação à nutrição do embrião em desenvolvimento, especialmente póscompactação. Blastocistos derivados de meio suplementado com PVA possuem perfil metabólico alterado quando comparados com embriões cultivados na presença de albumina ou produzidos in vivo. A formulação de qualquer sistema de cultivo em condições definidas deve ser capaz de suprir o embrião com todos os seus requerimentos fisiológicos (Thompson, 2000).

\section{Fêmeas receptoras}

A compra e manutenção de receptoras correspondem a uma considerável proporção dos custos da TE, sendo de extrema importância na determinação do número de produtos que podem ser gerados. Ainda, a identificação do número ótimo de receptoras é de grande valor econômico (Pereira et al., 2010). Usualmente, o número de receptoras a serem alocadas para um programa de TE ou PIV é calculado com base no número médio de embriões produzidos por doadora (Bó et al., 2000).

Os métodos disponíveis para o tratamento de receptoras de embriões incluem a indução de estro com o uso da prostaglandina F $2 \alpha$ ou seus análogos sintéticos e o emprego de hormônios para a sincronização da ovulação para TETF. A utilização de análogos da prostaglandina para indução de estro é um dos métodos menos dispendiosos para obtenção de receptoras aptas à transferência de embriões.

O uso de protocolos de sincronização de estro ou de ovulação em receptoras de embrião tem como objetivo a obtenção de animais em fase do ciclo estral compatível com a fase de desenvolvimento embrionário. Entretanto, existem algumas condições imprescindíveis para seu uso, tais como, a detecção do corpo lúteo por palpação retal ou ultrassonografia e observação do comportamento estral nos dias subsequentes ao tratamento (Barreiros et al., 2006).

Nos bovinos são empregados inúmeros protocolos hormonais que controlam o desenvolvimento folicular e a função lútea permitem a inseminação artificial (IA) em momento pré- determinado, superestimação ovariana, potencializando a eficiência reprodutiva (Buratini Júnior, 2007).

Em razão de taxas adequadas de ovulação, o uso destes protocolos permite a transferência de embriões em tempo fixo sem prévia observação de cio, empregando apenas a avaliação do corpo lúteo no momento da inovulação dos embriões. Além de facilitar consideravelmente o manejo, as taxas de aproveitamento estão em torno de $70 \%$ dos animais tratados para protocolos de TETF (Barreiros et al., 2006). 
A identificação e seleção de receptoras de alta qualidade não são simples. Vários estudos têm relatado variável que influenciam os resultados da sincronização de receptoras (Carvalho et al., 2008).

\section{Considerações finais}

Desde 2006, vem sendo registrado um crescimento médio de $28 \%$ no número de embriões FIV produzidos e uma diminuição de $73 \%$ na produção de embriões In Vivo. Com bases nesses dados acredita-se que o Brasil continuará liderando na produção de embriões In vitro e passará a fornecer cada vez mais genética a países interessados.

O crescimento da produção de embriões, por sua vez, dependerá de inúmeros fatores, mas espera-se que o Brasil, mantenha um crescimento entre 5 a $7 \%$ por ano, estabilizando sua produção, consolidando-se definitivamente no mercado.

E importante salientar que outros mercados são aquecidos com o aumento da produção de embriões, a exemplo temos a realização de exames DNA que comprovam a paternidade do animal para finalidades de registro.

\section{Referências Bibliográficas}

ABCZ. 2014. Programa de Melhoramento Genético de Zebuinos. Controle de Desenvolvimento Ponderal. Associação Brasileira de Criadores de Zebu, Uberaba.

Barreiros, T. R. R., Blaschi, W., Borsato, E. A., Ludwig, H. E., Silva, D. R. M. \& Seneda, M. M. 2006. Comparação das taxas de prenhez entre receptoras com corpos lúteos cavitários ou compactos após protocolos de sincronização com clorprostenol ou transferência de embriões em tempo fixo. Semina: Ciências Agrárias, 27, 657-664.

Bó, G. A., Adans, G. P. \& Mapletoft, R. J. 2000. Dinâmica folicular ovárica em El bovino. In: Madureira, E. H. \& Baruselli, P. S. (eds.) Controle farmacológico do ciclo estral em ruminantes. Funvet, São Paulo, Brasil.

Bols, P. E. J., Jorssen, E. P. A., Goovaerts, I. G. F., Langbeen, A. \& Leroy, J. L. M. R. 2012. High throughput noninvasiveoocytequalityassessment: thesearch continues. Animal Reproduction, 9, 420-425.

Brackett, B. G., Bousquet, D., Boice, M. L., Donawick, W. J., Evans, J. F. \& Dressel, M. A. 1982. Normal development followingin- vitrofertilization in thecow. Biology of Reproduction, 27, 147-158.

Buratini Júnior, J. 2007. Controle endócrino e local da foliculogênese em bovinos. Revista brasileira de Reprodução Animal, 31, $190=196$.

Carvalho, J. B. P., Carvalho, N. A. T., Reis, E. L., Nichi, M., Souza, A. H. \& Baruselli, P. S. 2008. Effect of early luteolysis in progesterone-based timed AI protocols in Bosi ndicus, Bos indicus $\times$ Bos taurus, and Bos taurus heifers. Theriogenology, 69, 167-175.

Edwards, R. G. 1981. Test-tube babies. Nature, 293, 253-256.

Galli, C. \& Lazzari, G. 2000. Practicalaspectsof IVM/IVF in cattle. Journal Reproduction Science, 42, 371-379.

Gonçalves, P. B. D., Visintin, J. A., Oliveira, M. A. L., Montagner, M. M. \& Costa, L. F. S. 2002. Produção in vitro de embriões. In: Gonçalves, P. B. D., R., F. J. \& Freitas, V. J. F. (eds.) Biotécnicas aplicadas à reprodução animal. Roca, São Paulo, Brasil.

Hafez, B. \& Hafez, E. 2004. Reprodução Animal. Manole: São Paulo, Brasil.

Keskintepe, L. \& Brackett, B. G. 1996. In vitro developmental competence of in vitromaturedbovineoocytesfertilizedandcultured in completelydefined media. Biology of Reproduction, 55, 333-339.

Lambert, R. D., Bernard, C., Rioux, J. E., Beland, R. \& Dàmours, D. 1983. Endoscopy in cattle by the paralombar route: technique for ovarian examination and follicular aspiration. Theriogenology, 20, 149-161.

Lim, J. M., Reggio, B. C., Godke, R. A. \& Hansel, W. 1999. Development of in vitro derived bovine embryos cultured in 5\% CO2 in air or in $5 \% \mathrm{O} 2,5 \% \mathrm{CO} 2$. and $90 \% \mathrm{~N} 2$. Human Reproduction, 14, 458-464.

Monniaux, D., Chupin, D. \& Saumande, J. 1983. Superovulatory response ofcattle. Theriogenology, 19, 55-81.

Pereira, E. S., Pimentel, P. G., Queiroz, A. C. \& Mizubuti, I. Y. 2010. Novilhas leiteiras. Graphiti Gráfica e Editora Ltda, Fortaleza, Ceará.

Pontes, J. H. F., Sanches, B., Ereno, J. J., Uvo, S., Barreiros, T., Oliveira, J., Hasler, J. \& Seneda, M. 2009. Comparison of embryo yield and pregnancy rate between in vivo and in vitro 
methods in thesame Nelore (Bos indicus) donorcows. Theriogenology, 71.

Pontes, J. H. F., Sterza, F. A. M., Basso, A. C., Ferreira, C. R., Sanches, B. V., Rubin, K. C. P. \& Seneda, M. M. 2011. Ovumpickup, in vitro embryo production, and pregnancy rates from a large-scale commercial program using Nelore cattle (Bos indicus) donors. Theriogenology, 75, 1640-1646.

Rigolon, L. P., Prado, I. N., Cavalieri, F. L. B., Nascimento, W. G., Copovila, L. C., Ramos, F. S. \& Moreira, F. B. 2009. Effect of the dry matter intake level on the sanguine profile of glucose, insulin, urea, estrogen and progesterone and concentration of IGF-I in the follicular liquid of crossbred heifers. Brazilian Archives of Biology and Technology, 52, 6168.

Rigolon, L. P., Prado, I. N., Cavalieri, F. L. B., Nascimento, W. G. \& Negrão, J. A. 2003. Effect of different levels of energy intake on production and viability of embryos in heifers and cows. Revista Brasileira de Zootecnia, 32, 1304-1310.

Rubin, M. I. B., Pessoa, G. A., Fraga, D. R., F.F., V. \& Silva, C. A. M. 2009. Produção in vitro de embriões e clonagem: um caminho conhecido? Revista Brasileira de Reprodução Animal, 6, 77-85.

Seneda, M. M., Esper, C. R., Garcia, J. M. \& Andrade, E. R. 2002. Aspectos técnicos e biológicos da obtenção de oócitos bovinos: revisão de literatura. Semina: Ciências Agrárias, 23, 101-110.

Sirard, M. A. 2017.The influence of in vitro fertilization and embryo culture on the embryo epigenetic constituents and the possible consequences in the bovine model. Journal of Developmental Origins of Health and Disease, 8, 411-417.

Sugimoto, H., Koto, K., Saeki, K., Taniguchi, T. \& Hosoi, Y. 2012. Growth and development of rabbit oocytes in vitro: effect of fetal bovine serum concentration on culture medium. Theriogenology, 15, 78, 1040-1047.

Thompson, J. G. 2000. In vitro culture and embryos metabolis cattle and sheep embryos a decade of achievement. Animal Reproduction Science, 60/61, 263-275.

Viana, J. H. M. \& Bols, P. E. J. 2005. Variações biológicas associadas a recuperação de complexos cumulus-oócitos por aspiração folicular. Acta Scientiae Veterinariae, 33, 1-4.

Viana, J. H. M. \& Camargo, L. S. A. 2007. A produção de embriões bovinos no Brasil: Uma nova realidade. Acta Scientiae Veterinariae, 3, 915-924.

Yang, W.-C., Yang, L.-G., Riaz, H., Tang, K.-Q., Chen, L. \& Li, S.-J. 2013. Effects in cattle of genetic variation within the IGF1R gene on the superovulation performance and pregnancy rates after embryo transfer. Animal Reproduction Science, 143, 24-29.

\section{Article History:}

Received 20 November 2017

Accepted 9 January 2018

Available online 19 February 2018

License information: This is an open-access article distributed under the terms of the Creative Commons Attribution License 4.0, which permits unrestricted use, distribution, and reproduction in any medium, provided the original work is properly cited. 